Pak. j. sci. ind. res. Ser. A: phys. sci. 2019 62A(3) 197-201

\title{
Role of Automotive Industry in Global Warming
}

\author{
Shahid Hussain Abro ${ }^{\mathrm{a} *}$, Alidad Chandio ${ }^{\mathrm{b}}$, Abdulaziz S. Alaboodi ${ }^{\mathrm{c}}$ and Iftikhar Ahmed Channa \\ Department of Materials Engineering, \\ ${ }^{a}$ Department of Materials Engineering, NED University of Engineering and Technology, \\ Main University Road, Karachi, Pakistan \\ ${ }^{\mathrm{b}}$ Department of Metallurgical Engineering, NED University of Engineering and Technology, \\ Main University Road, Karachi, Pakistan \\ ${ }^{c}$ Department of Mechanical Engineering, Qassim University Kingdom of Saudi Arabia \\ ${ }^{\mathrm{d}}$ Friedrich University of Erlangen Nuremberg, Germany
}

(received June 21, 2018; revised November 19, 2018; accepted January 7, 2019)

\begin{abstract}
Global warming and air pollution by human made gases such as $\mathrm{CO}_{2}$, is mainly produced by automotive industry that results in great risk for human health. The aim of this study is to reduce the above problem by using the high strength materials with low density in the manufacturing of automotive vehicles. An approach applied here is to enhance the strength by reducing the grain size, lowering the density and increasing elongation. Four steel samples with different chemical compositions were selected. Samples were heat treated from $850{ }^{\circ} \mathrm{C}$ to $1250{ }^{\circ} \mathrm{C}$ and cooled in water. Grain size distribution was calculated using matrox inspector software and result was plotted using origin. It was found that $850{ }^{\circ} \mathrm{C}$ has lowest and $1250{ }^{\circ} \mathrm{C}$ has highest grain sizes. Strength of steel can be increased not only by adding the alloying elements but also by controlling grain size. Light weight material consumes lower fuel and emits lower $\mathrm{CO}_{2}$, thus it minimizes the global warming and air pollution.
\end{abstract}

Keywords: global warming, $\mathrm{CO}_{2}$ emission, light weight, low fuel consumption, grain size.

\section{Introduction}

The automotive industry has increased the weight of cars due to increasing people's luxury and safety which leads to consume higher energy in the form of fuel and obviously increasing the global warming and air pollution (Ángel et al., 2017). Due to these effects the temperature of earth can further increase in the coming years. The share of automotive industry in global warming in the form of $\mathrm{CO}_{2}$ is roughly about $17 \%$ (Afnan et al., 2017). Since last twenty five years competition among the safe, light, and more fuel economic land vehicles demand has significantly increased to high level (Alidad et al., 2018). In this challenging task of achieving significant reduction in global warming and fuel economy, many researchers investigate the TRIP and TWIP steels (Johnsan et al., 2017). Strength to weight ratio is a hot issue for the steel researchers. The usual trend to decrease the sheet thickness ratio and increasing the strength, researchers increase the amount of manganese, however $\mathrm{Mn}$ is considered to be little bit expensive (Kuimov et al., 2016). Therefore, there is a strong driving force for steel makers to design and develop a microstructure

\footnotetext{
*Author for correspondence; E-mail: engrabro@neduet.edu.pk
}

and grain size of the steel to achieve high strength, high hardness and low density of the steel structure (Jian Chai et al., 2016). The components of automotive cars and the whole body of the passenger vehicles can reduce total weight of the vehicles (Jinwon et al., 2016), consequently it can reduce the fuel consumption and reduction in fuel automatically reduces the $\mathrm{CO}_{2}$ emission in the air thus reducing the global warming effect in Pakistan.

\section{Materials and Methods}

Four steel samples were made six in numbers to investigate the effect of grain size on the strength properties and subjected to heat treatment. Each specimen was soaked at the specific temperatures for the time periods as shown in Fig. 1. After heat treatment samples were rapidly cooled in tape water. Samples were cut in perpendicular direction at the rolling plane and were brought to basic metallographic investigation by using grinding followed by polishing. The polishing agent was the diamond paste made from alumina.

Heat treatments were followed by metallography and microscopy to reveal the changes due to micro alloy addition and their resulting precipitation. By resulting 


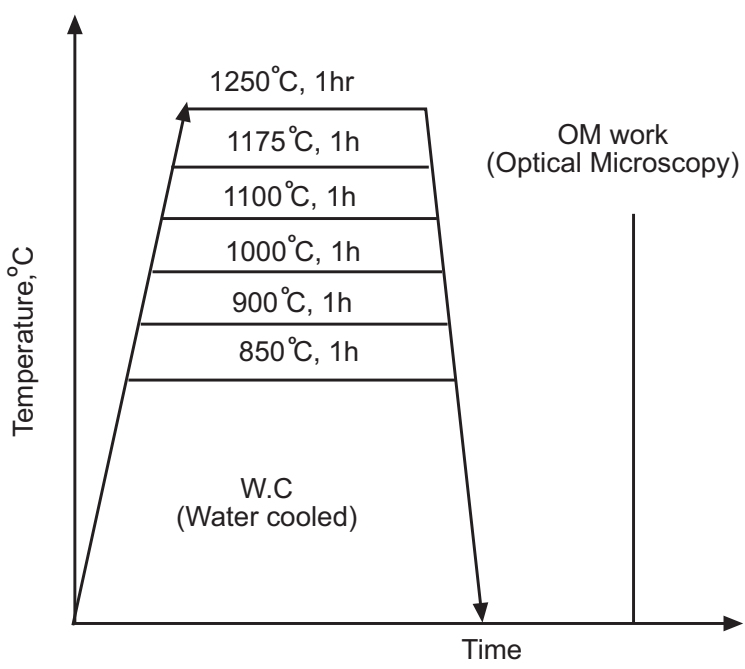

Fig. 1. Heat treatment cycles to be followed.

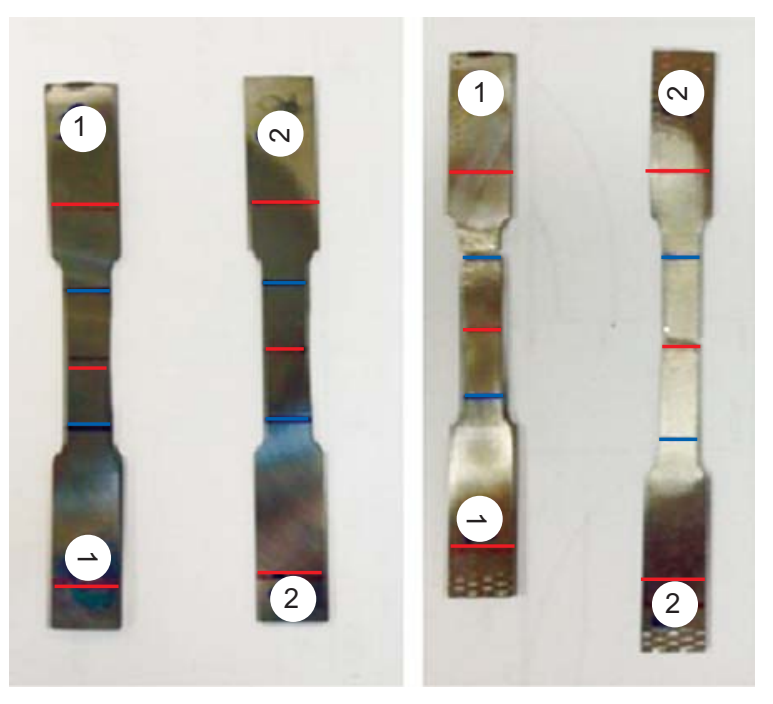

Fig. 2. Tensile samples of the steel.

microstructure and using the software matrox inspector the GSD (Grain Size Distribution) histograms and sizes were obtained (Nicholas et al., 2016) as shown in the Figure 3-6. Two steel samples as shown in Fig. 2 were prepared for tensile testing to know the effect of grain size in each.

\section{Results and Discussion}

Firstly samples of the steel under investigation in this research work were treated with heat at $1250^{\circ} \mathrm{C}$ followed by water quenching. All the four steel samples were observed under different soaking temperatures with fixed time of $60 \mathrm{~min}$ each. Microstructure preparation was carried out by using conventional metallography and etching technique with $2 \%$ Nital solution. After revealing the structure each sample's grain size distribution was calculated using latest metrox inspector software (Qi Zhang et al., 2018). Higher strength was achieved at lower heat treatment temperature and it was the indication that not only by alloying elements can increase the strength of steel used for automotive parts manufacturing but combination of heat treatment parameters can also increase the strength property (Ralf et al., 2017). This conceptual skill can be utilized to adopt strength to weight ratio of the automotive steels thus it is not only the cost effective but will minimize the weight of passenger vehicles without scarifying of strength (Shahid et al., 2018). The heat treatments of the four samples are shown in Fig. 3-6 along with their grain size distribution. Each experiment is performed to investigate that which steel sample has high strength properties because the steel material is widely used for car bodies and other small machine components which increases the overall weight of the land vehicle that consume high energy fuel. By utilizing the lightweight materials during manufacturing in the plant may minimize this problem. It is always the trend to use the high alloyed steels to obtain the high strength. But this not only increase the cost but also the weight of the steel itself.

Figures 3-6 indicates the grain sizes of the experimental steel with respect to holding time and temperature in the heat treatment furnace. In Fig. 3 the mean grain size $\mathrm{D}_{0}$ of the experimental steel is $12.19 \mu \mathrm{m}$ at a temperature of $850{ }^{\circ} \mathrm{C}$ and the mean grain size increases by increasing the temperature i.e., $\mathrm{D}_{0}$ is $40.03 \mu \mathrm{m}$ at $1250{ }^{\circ} \mathrm{C}$. By following the same methodology in Fig. 4-6 mean grain sizes increase with increasing temperature. To achieve the higher strength grain size of the steel should be low because finer grain size materials may exhibit higher strength with low weight (Bhagat et al., 2018; and Martin et al., 2008). Reduction in grain size may also increase in the tensile strength by applying high yield stress and lower elongation as shown in Fig. 7 (Chandrashekar et al., 2009).

The high percentage of elongation is possible with higher grain size at lower yield stress as indicated by the tensile testing results, shown in Fig. 8 (The testing 

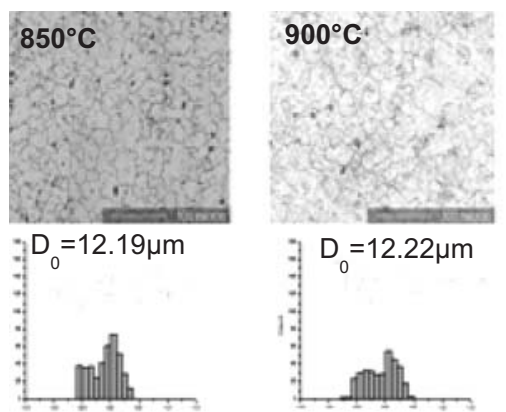

$1100^{\circ} \mathrm{C}$

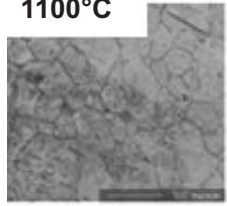

F $D_{0}=33.17 \mu \mathrm{m}$

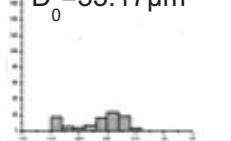

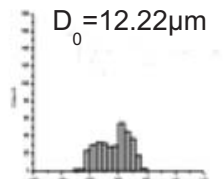

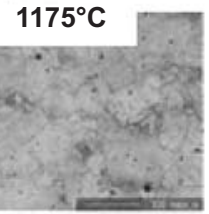

7. $D_{0}=37.89 \mu \mathrm{m}$
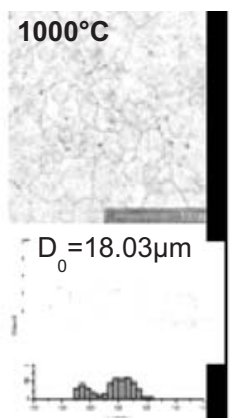

$1250^{\circ} \mathrm{C}$

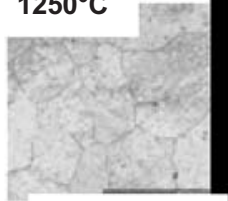

$\mathrm{D}_{0}=40.03 \mu \mathrm{m}$

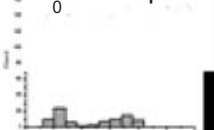

Fig. 3. specimen \# 1 (Soak time: 1 h.).

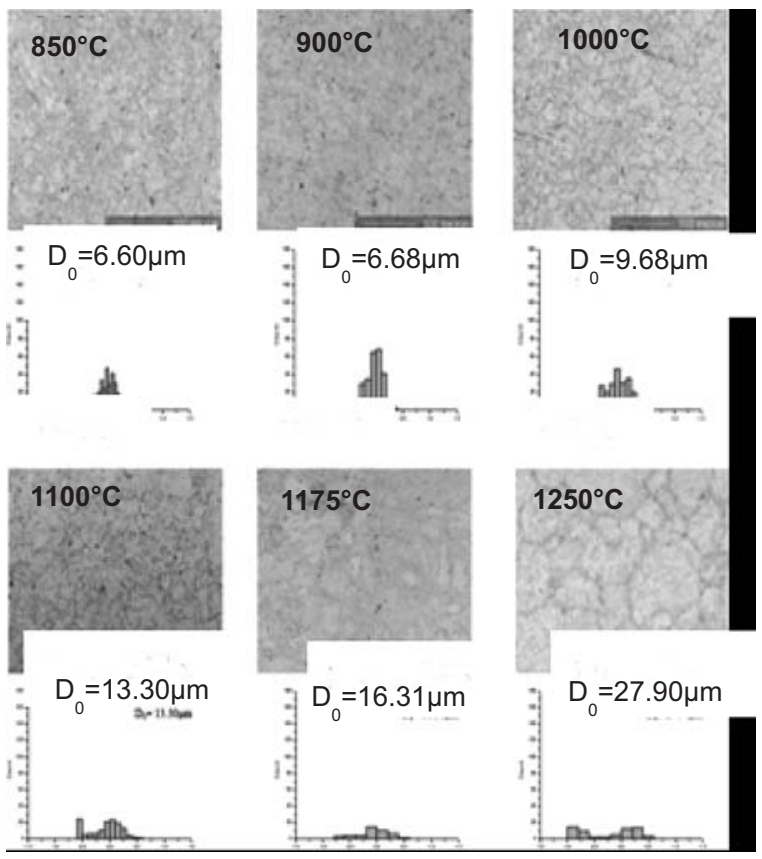

Fig. 4. specimen \# 2 (Soak time: 1 h.)

samples of both conditions have been shown in Fig. 2). It means higher strength to weight ratio is achievable in the experimental steel under investigation having
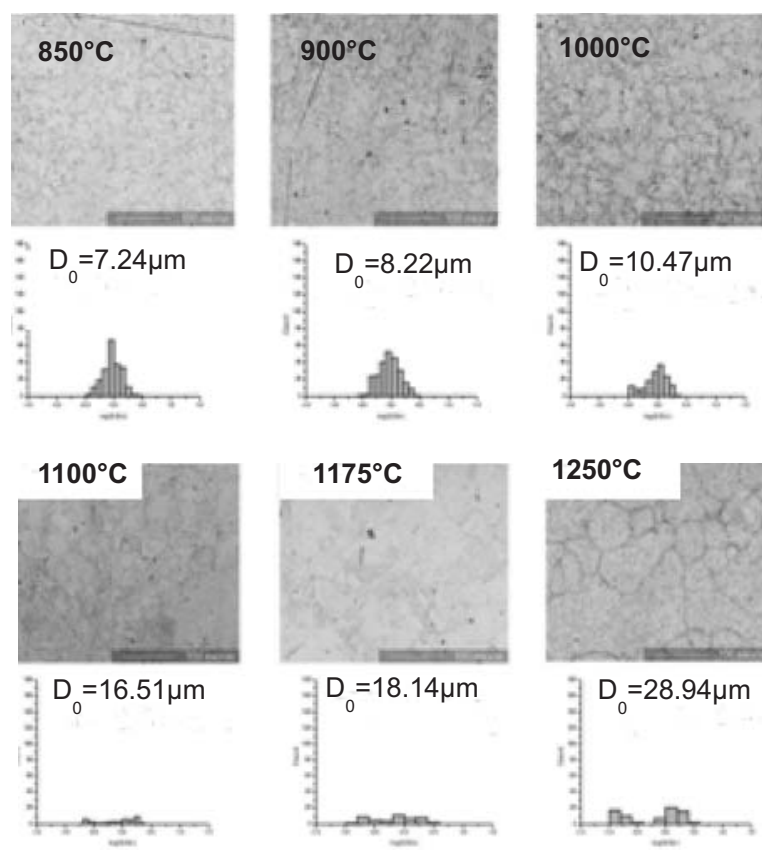

Fig. 5. Specimen \# 3 (Soak time: 1 h.)
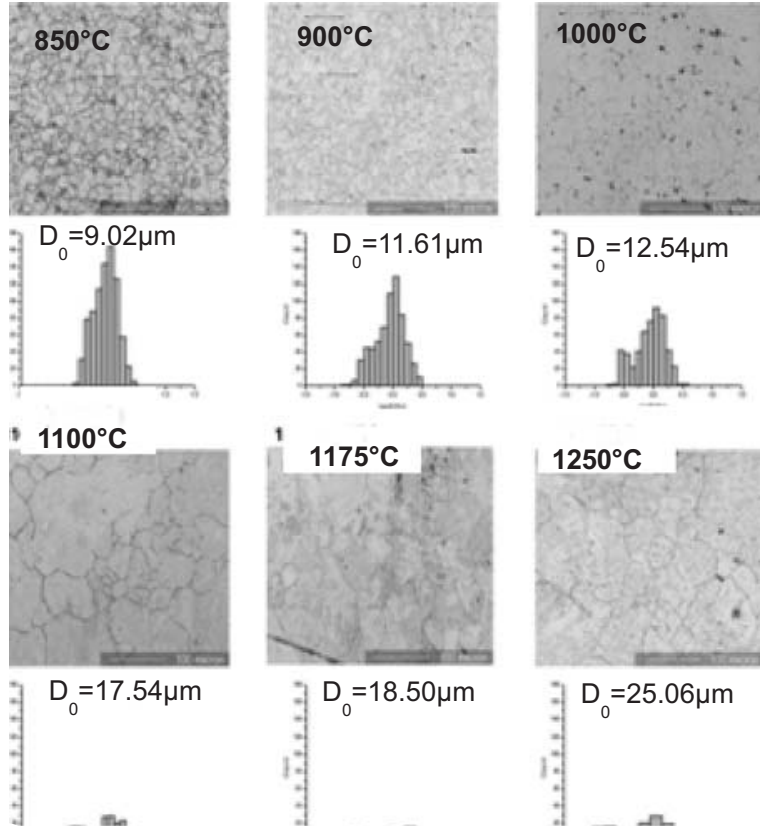

Fig. 6. specimen \# 4 (Soak time: 1 h.)

fine grain size. Majority of automotive components are made from ferrous material like steel so there is a strong driving force for steel manufacturers to decrease the 


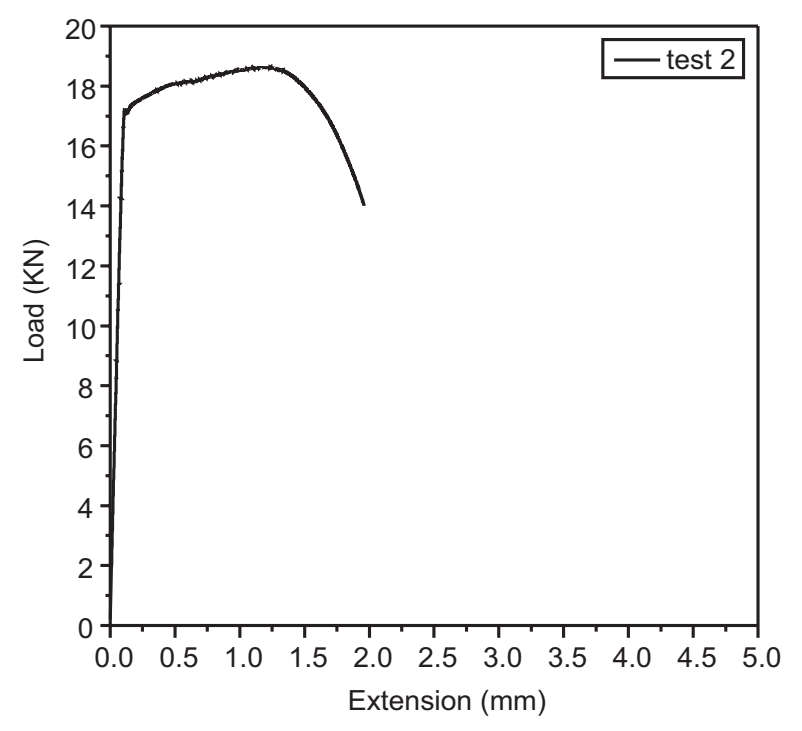

Fig. 7. Tensile testing results of $850^{\circ} \mathrm{C}$.

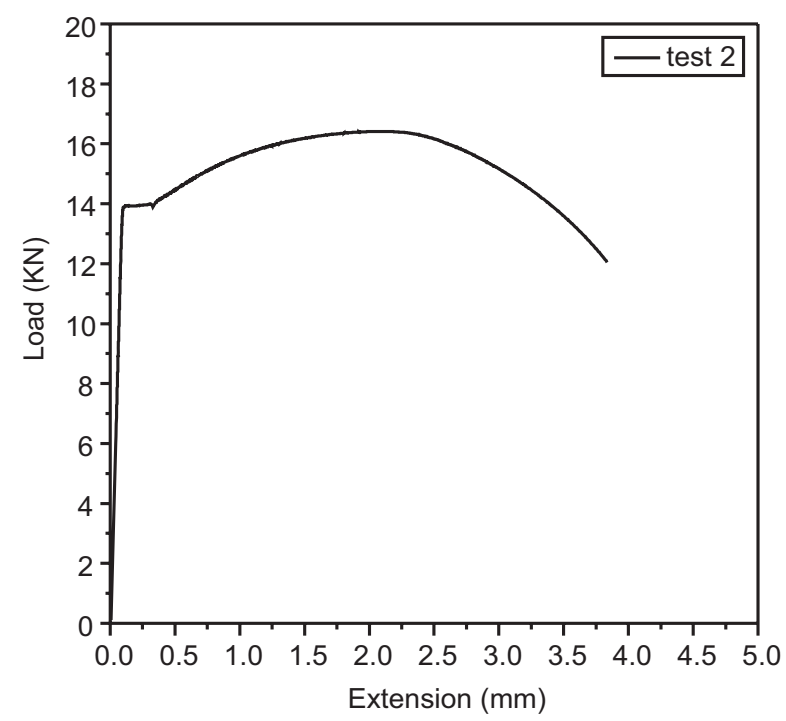

Fig. 8. Tensile testing results of $1250^{\circ} \mathrm{C}$.

density of steel (Lin et al. 2018; Shan et al., 2018; Xiaoxin et al., 2017). Tensile testing results show that finer grain size sample has higher elongation rate comparing with coarse grain size.

\section{Conclusion}

This study was carried to observe the effect of grain size control and resultant microstructure on the grain size distribution and $\%$ elongation on the strength of the experimental steel used for automotive industry. Its effect on air pollution and global warming in Pakistan has also been studied using heat treatment design and tensile testing machine available locally. It was found that there is a strong relation between grain size and strength. Strength can be increased by decreasing the mean grain size of the experimental steel which can be used in automotive industry for making different functional parts of the land vehicles and reduce the overall weight by scarifying the higher number of alloying elements. In this way low energy will be consumed in the form of gasoline and emission of $\mathrm{CO}_{2}$ gases in the environment will be lesser in quantity and diminish the global warming produced by the vehicles.

\section{Acknowledgement}

Authors of this article are very much thankful to Department of Materials Engineering at NED University of Engineering and Technology for providing lab facilities and experimental equipments.

Conflict of Interest. The authors declare no conflict of interest

\section{References}

Abro, S.H., Chandio, A.D., Aftab, U. 2018. Effect of heating rate on microstructural developments in cold heading quality steel used for automotive applications. Mehran University Research Journal of Engineering \& Technology, 37: 461-466.

Cao, S.C., Linli, Z., Jiabin, L., Ge, W., Wenxuan H., Jian, L. 2018. Light-weight isometric-phase steels with superior strength-hardness-ductility combination, Scripta Materiala, 154: 230-235.

Chandio, A., Abro, S.H. 2018. Effect of temperature and time on nickel aluminide coating deposition. Mehran University Research Journal of Engineering \& Technology, 37: 481-486.

Chandrashekar, T., Muralidhara, M.K., Kashyap, K.T., Raghothama Rao, P. 2009. Effect of growth restricting factor on grain refinement of aluminum alloys. The International Journal of Advanced Manufacturing Technology, 40: 234-241.

Derek, R.J., Robert, H., Andrew, C.N., Nigel, C., Mahdi, D. 2017. Greenhouse gas emissions and fuel efficiency of in-use high horsepower diesel, dual fuel and natural gas engines for unconventional well development. Applied Energy, 206: 739-750.

Freije, A.M., Hussain, T., Salman, E.A. 2017. Global warming awareness among the University of 
Bahrain science students. Journal of the Association of Arab Universities for Basic and Applied Sciences, 22: 9-16.

Hannappel, R. 2017. The impact of global warming on automotive industry. American Institute of Physics, AIP Conference Proceedings, 1871, 060001.

Jian, C., Ying, Y., Shouyang, W., Keung. L.K. 2016. Fuel efficiency and emission in China's road transport sector: Induced effect and rebound effect. Technological Forecasting and Social Change, Elsevier, 112: 188-197.

Kempf, N., Zhang, Y. 2016. Design and optimization of automotive thermo-electric generators for maximum fuel efficiency improvement. Energy Conversion and Management, 121: 224-231.

Kim, J. 2016. Vehicle fuel-efficiency choices, emission externalities, and urban sprawl. Economics of Transportation, 5: 24-36.

Kuimov, E.A., Plotnikov, S.A. 2016. Evaluation of the economic efficiency of various alternative fuels in transport. Procedia Engineering, 150:1209-1214.

Lin, Y., Pan, J., Zhou., H. 2018. Mechanical properties and optimal grain size distribution profile of gradient grained nickel. Acta Materialia, 153: 279-289.

Medina, Á., González-Jartín, J.M., Sainz, M.J. 2017. Impact of global warming on mycotoxins. Current Opinion in Food Science, 18: 76-81.

Pugazhendi, B.S., Sinnaeruvadi, A.K.K., Suwas, S. 2018. Effect of aluminum on microstructure, mechanical property and texture evolution of dual phase $\mathrm{Mg}-8 \mathrm{Li}$ alloy in different processing conditions. Archives of Civil and Mechanical Engineering A, 18: 1332-1344.

San Martín, D., Rivera-Díaz-del-Castillo, P.E.J., Garcíade-Andrés, C. 2008. In situ study of austenite formation by dilatometry in a low carbon microalloyed steel. Scripta Materialia, 58: 926-929.

Wang, X., Jiang, D., Lang, X. 2017. Future extreme climate changes linked to global warming intensity. Science Bulletin, 62: 1673-1680.

Zhang, Q., Yu, L., Jin, X., Guoyu, J. 2018. Carbon element flow analysis and $\mathrm{CO} 2$ emission reduction in iron and steel works. Journal of Cleaner Production, 172: 709-723. 